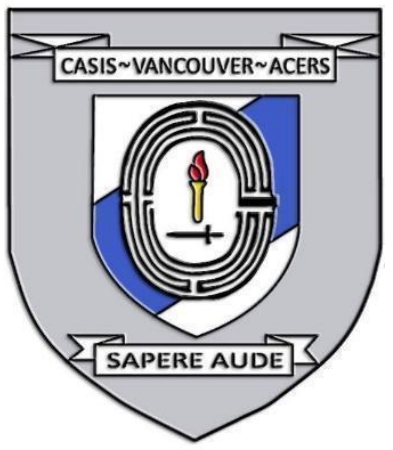

DRONE WARFARE IN TRANSNATIONAL ARMED CONFLICT AND COUNTERTERRORISM

Date: November 23, 2020

Disclaimer: This briefing note contains the encapsulation of views presented by the speaker and does not exclusively represent the views of the Canadian Association for Security and Intelligence Studies.

\title{
KEY EVENTS
}

On November 23, 2020, Dr. James Patrick Welch presented on the topic of Drone Warfare in Transnational Armed Conflict and Counterterrorism at the 2020 CASIS West Coast Security Conference. The presentation was followed by a moderated question and answer period. Key points of discussion included: the ethics surrounding drone warfare, drone proliferation, accountability, and AI technology in drone warfare.

\section{NATURE OF DISCUSSION}

\section{Presentation}

Dr. James Patrick Welch discussed the emergence of drone warfare and the legal, ethical, and strategic use of drones in transnational armed conflict and counterterrorism.

\section{BACKGROUND}

\section{Presentation}

While drone warfare has become a popular subject due to its increasing presence in headlines around the globe, the use of drones and drone warfare are hardly new concepts. For example, Joseph Kennedy Jr., older brother of John F. Kennedy, died in 1944 during a top secret mission involving an unmanned aircraft. In modern conflicts where potential prisoners of war face brutal consequences, as in the case of the Jordanian pilot captured by ISIS, drone warfare is being increasingly looked upon to preserve the safety fighting forces. 
Though the use of drones in warfare is currently legal, how drones are used deserves serious debate. This debate flared up most intensely during the Obama administration, with Obama earning the unofficial title of the "Drone King". Within the discussion surrounding drone warfare, there remains more debate and conflict than actual consensus. A common mistake among drone-using nations is to use the technology as a strategy as opposed to a tactic. American General Stanley McChrystal has said that "using the predator [drone] is a tactic, not a strategy". When we use drones as a strategy as opposed to as a tactic, we overlook things like diplomacy, regulation, and enforcement.

Another major issue surrounding drone warfare is proliferation. While debates are still being had about the ethicality of the various uses of drones in warfare, the market for drones is booming. A particularly dangerous aspect of the proliferation of drones is the increasing use of off-the-shelf drones in warfare. As drones become more complex, capable, cheaper, and widely available, they are being increasingly employed on battlefields across the globe.

Accountability is another issue prevalent in drone warfare. The accessibility of drones is upsetting regional balances of power. Responsibility for the increased prevalence of drones is commonly debated. When fatalities occur as a result of drones, there is an issue of placing responsibility as well. Plausible deniability is ever present. False flag operations may become a serious issue in the future of drone warfare as well. Violent actors will be able to commit violence using drones, and deny their involvement for lack of evidence.

As AI technology continues to advance, we will soon see fully autonomous drones being used in warfare. The ethics of drones in warfare must be heavily debated and decided upon before we reach this stage, as ethical decisions will have to be programmed into AI operated drones. Without having this debate, the ethics programmed into these autonomous drones will be at the discretion of their programmer.

\section{KEY POINTS OF DISCUSSION}

\section{Presentation}

- Drone warfare is not a new concept.

- The use of drones in warfare is legal, it is how drones are used in warfare that is debated. 
- Drone usage as a tool/tactic, not as a strategy which supersedes diplomacy, regulation, and enforcement.

- Drone proliferation is an issue that needs to be watched.

- Accountability needs to be seriously considered moving forward.

- Conflicts short of war, or low intensity conflicts are becoming a difficult grey zone.

- Swarm attacks are becoming a real-world threat.

- In the future we will see fully autonomous drones as AI technology advances.

\section{cc) $($ ) $९ \ominus$}

EY NC ND This work is licensed under a Creative Commons AttributionNonCommercial-NoDerivatives 4.0 International License.

(C) (James Patrick Welch, 2021)

Published by the Journal of Intelligence, Conflict, and Warfare and Simon Fraser University

Available from: https://jicw.org/ 